\title{
Safety assessment of glycol recovery unit in a gas refinery by failure mode and effects analysis technique
}

\author{
Mahdavi S, MSc ${ }^{1}$, Rasti Pisheh P, BSc ${ }^{2}$, Jozekanaani M, MSc ${ }^{3 *}$ \\ 1- Faculty Member, Dept. of Occupational Health Engineering, School of Health, Lorestan University of Medical Sciences, \\ Khorramabad, Iran. 2- MSc Student of Occupational Hygiene Engineering, Tehran University of Medical Sciences, Tehran, \\ Iran. 3- MSc in Occupational Hygienist, Governing Health Section, HSE Main Office, National Iranian Gas Company \\ (NIGC), Tehran, Iran
}

\begin{abstract}
Received: November 2016, Accepted: February 2017

Background: The reliability and safety of gas refineries are strongly associated with the reliability of other parts of the system. Defect and failure in one part of a system can cause total system breakdown or accident. The failure and damage in these equipment such as transformers and boilers results in not only the equipment damage and human injuries but also productivity reduction. The purpose of this study was safety assessment of glycol recovery unit in gas refinery by failure mode and effects analysis (FMEA) technique.

Materials and Methods: The present study is a descriptive-analytical study done for risk assessment of glycol recovery unit of a gas refinery in one of the southern areas of Iran. FMEA method was used to identify and detect possible failures in the system. Failure modes of a component and their causes were identified and effects of identified failures were examined, then the necessary corrective measures were recommended.

Results: In this research, 105 failure modes were studied. The highest risk priority number (RPN) values obtained were 150 (while removing corrosion and welding inside TK601A/B vessel which was due lack of air ventilation) and 120 (while installing the gasket).

Conclusions: FMEA technique is a useful method to prevent accidents and increase safety and productivity. FMEA can identify and assess potential risks and propose corrective action required to control the risks.
\end{abstract}

Keywords: Safety, Risk Assessment, Failure Mode and Effect Analysis

\section{Introduction}

The performance of a system and installation, especially complex systems, requires a high level of safety and reliability that is created by safety instructions and strong safety culture. Ignoring these instructions may lead to adverse consequences for a system, installation, human and environment. So providing the system in a safe state by personnel and management is important not only for processing units of that system but also for the whole system and installation (1). According to safety definition that states the level of escaping from hazard, the first stage in installing and improving safety level in a workplace is identifying the hazard (2) and the next step is hazard assessment (3). There are different methods for assessment such as HAZOP (Hazard and Operability Study), LOPA (Layer of Protection Analysis) and failure mode and effects analysis (FMEA). It should be noticed that selection of appropriate method for assessment and identification of hazards has important role, so that use of HAZOP in chemical processes and FMEA for equipment systems are considered (3). In other words, one of the important components of a safety system management is the identification of potential process failure modes and their associated consequences. Hence, high

\footnotetext{
* Corresponding author: Masoumeh Jozekanaani, Governing Health Section, HSE Main Office, National Iranian Gas Company (NIGC), Tehran, Iran.

E-mail: jozekanaani@nigc.ir
} 
reliability and safety of factories, installations and systems such as petrochemical industries, oil and gas refineries should be assured continuously (4).

In order to maintain safety of systems and installations by identifying potential failure modes, FMEA technique could be considered as an efficient method. This technique is an organized methodology for analysis of failure causes and its effects. The method was first introduced by the US military forces (MIL-P1629) in 1949 that recently has got an inseparable part of ISO-9000 and QS-9000 (5). Also, this technique was applied with obvious requirements of reliability and safety by airplane manufacturing enterprise in 1960 and then developed in other industries such as automobile industries, oil and gas refineries. The aim of FMEA is identification and prioritization of possible failures in products and processes (6).

A study performed using FMEA method by Arabian et al. (5) in 2010 to identify the current failure modes in power producing systems, presented that FMEA method has the ability to improve the reliability of wind turbine systems so that the reliability has a role in anticipation and cost efficiency. Moreover, FMEA method has an important role in development and better design of wind turbines. This technique could be a useful instrument for designers to identify the weak points in designing the turbine. In the study of a turbine, 16 failure modes in 107 parts of studied system were identified (7).

Also, Wang et al. (3) studied development of risk management by FMEA for continuous catalyst correction to evaluate the human damage severity and environmental pollution. The results illustrated that FMEA is useful in identifying the crisis condition (4).

In other study, Dudek et al. (8) used FMEA as a method to monitor the process of production in an organization. He illustrated that this method can help to identify the potential failure and other failures that are effective in the process of production.
The study of Lipol et al. showed that although FMEA has been designed to identify the current potential failure in a product or a process and to assess the risk before occurrence, this method is practical in designing process and development of a system or product. Conducting this method in the stages of process activity or existing products contributes to productivity too (9).

Carazas et al. applied FMEA to determine the performance of the most critical parts of turbine and gained the valuable qualified information about designing and performance of system. Based on this method, 24 failures were found for one of the turbines with 5-years life time activity that 12 failures were related to the first 2 years of turbine life which resulted from the problems of calibration for pressure gauge that was in exhausting collector, and other failures were for deficiency of cleaning the fuel filters that resulted in making the filter gluey and heavy and weakening the quality of natural gas (10). Alinezhad et al. used FMEA and ETBA (Energy Trace \& Barrier Analysis) to assess the safety of circle liquid gas vessels. According to FMEA method, 29 potential failures were identified of which the highest risk priority number (RPN) was 294 and the lowest was 48 with unacceptable failure as PRN > 100 (11).

Alimohammadi and Adl surveyed the safety of 2 gypsum factories by FMEA method. The results showed that the highest rate of failure in studied furnaces was related to split and deformation of hooves the head and bottom of the furnace (12).

In other study that was performed by Heidari et al. in a pharmacy factory, it was discussed that when using the FMEA method, the accurate understanding of system and also accurate recognition of hazard are necessary in order to consider the accurate figures for occurrence possibility and risk severity, because inaccurate consideration of these figures would result in error in accident control (13). So applying this technique is required to complete knowledge of system. 
It is necessary to remind that FMEA technique surveys the system or subsystems in order to identify the possible failures of all the components. It tries to assess the effects of the possible failures on other components of the system. The most important results of this technique are determination of vulnerable items of the process and critical zones of the system. These results will have significant effects on hazard reduction and cost of operation and maintenance with considering quantified index of each fault. The hardware view point of FMEA to the system provides the early recognition of potential failure modes and their elimination in order to decrease the possible losses and also improve the safety level and process reliability (11).

The reliability of glycol unit is very important for the performance of a refinery. Glycol is injected to separation centers and dew point regulating unit in order to absorb the water from the gas and to prevent creating hydrate. So this unit has an essential role in gas treatment and refinement in gas refinery.

According to this subject, the failure and damage of equipment in this unit such as transformers and boilers not only could result in damages to the equipment and human injuries, but also reduction of proficiency. Thus FMEA method is a deductive method that is handled for assessing the effects of potential modes of systems, parts and functional duties. In addition, FMEA has the ability to identify the failure modes that may affect the capability of the whole system. Engineering technique to identify the possible failure in the system is studied and applied to assess the safety statues of glycol recovery unit in gas refinery. For this purpose, after careful study of the system process, the functions and system components were identified, failure modes of portions and causes of them were determined, the effects of identified failures were surveyed and controlling recommendations and solutions were presented.

\section{Material and Methods}

The current study was a descriptive-analytical research performed in glycol recovery unit of a gas refinery in one of the southern areas of Iran. This unit has lines to separate glycol from liquid hydrocarbon and a glycol condensation machine. The machine includes two condensation towers which one of them is spare and the other works as usual one. Glycol storage unit has condensate glycol storage vessel. In this unit, failure mode of different parts of the system such as aspirator, transformer, coil boiler, pumps, storage vessels and fans were assessed by FMEA method. The process of performing this study was as following:

1. The researchers made a research and assessment team that included Health, Safety and Environment (HSE) supervisor, process and product engineer, mechanic engineer and researchers.

2. The research team studied the system carefully in the aspects of the main function of the process, the function limitation of the whole system and its components by means of observation, interviewing with experts and surveying the guidelines.

3. Then, they identified the critical, sensitive points of the system and those with high accident potential in each section of the vessel body including safety valve, gage, pumps, transformers, boilers and separator.

4. Also, the weakness of a component or an activity about doing an early determined task was surveyed.

5. The effect of a component fault on other parts was assessed.

6. The severity of the effect of fault on system or people was surveyed.

7. The real reasons of fault for a component or an activity was studied.

8. The probability of fault in a component or an activity during a specific period was determined.

9. Also, all controls and actions that had been performed for prevention of fault occurrence 
or reduction of its severity and probability were studied.

10. After studying the important points, critical components, sensitive and high potential points, failure modes of components, the reasons and effects of identified faults, the severity and probability and recovering of each case were surveyed. RPN was calculated by multiplying three mentioned factors.

11. Then controlling and corrective recommendations and solutions were offered and entered in FMEA worksheet.
Figure 1 illustrates the stages of FMEA method as following:

- $\quad$ Studying the potential failure modes of the system

- Surveying the potential effects of failures

- $\quad$ Surveying the reasons of failures

- $\quad$ Studying and assessing the process of existing controls

- $\quad$ Calculating the RPN

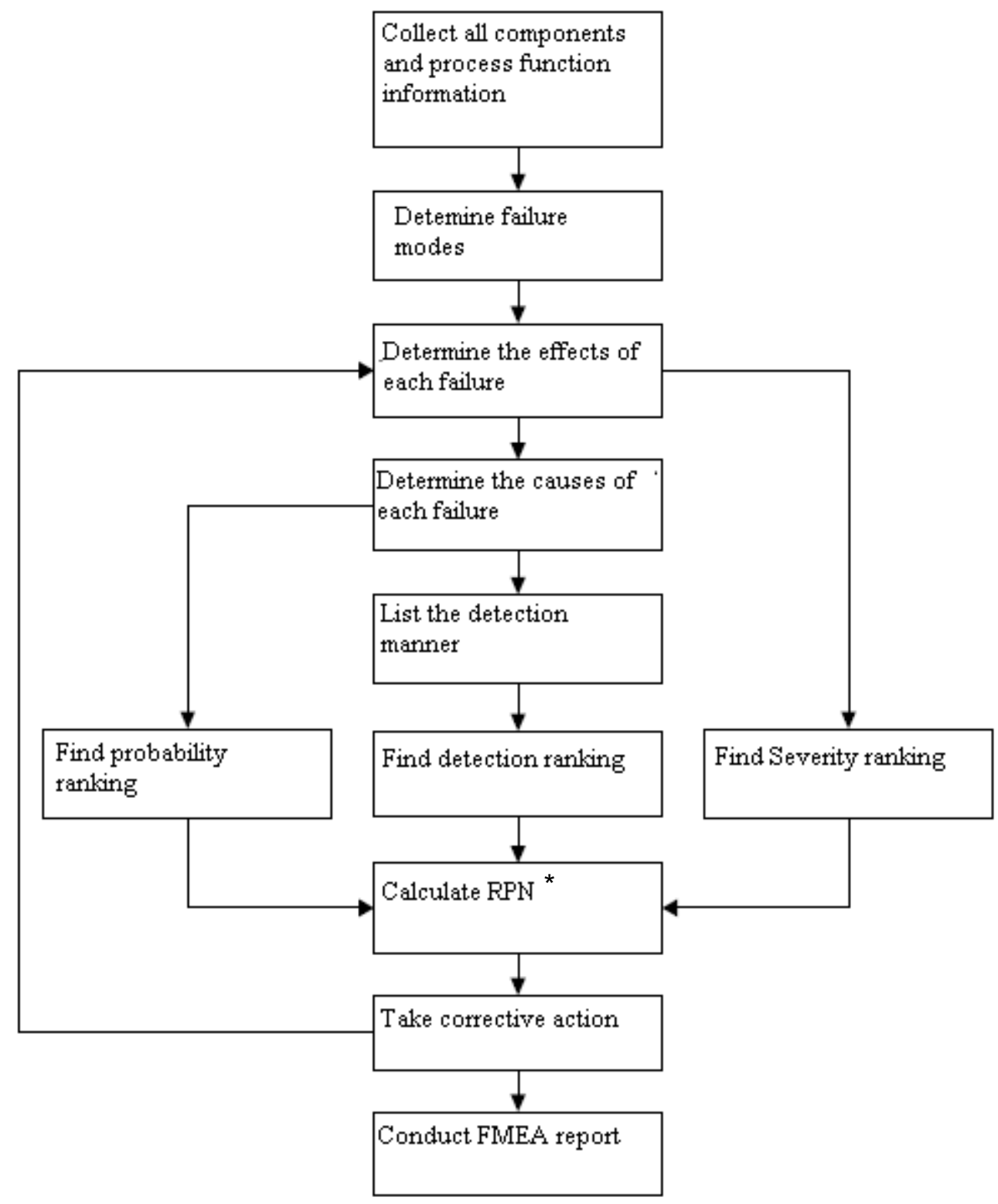

Figure 1: Failure mode and effects analysis (FMEA) process (6)

*RPN: Risk priority number 
Table 1: Severity of effect

\begin{tabular}{ccc}
\hline Ranking & Severity of effect & Description \\
\hline 10 & Dangerous-without alarm & Catastrophic such as danger of death and complete destruction \\
\hline 9 & Dangerous-with alarm & Catastrophic but with alarm \\
\hline 8 & Too high & Irreparable, disability of doing main task-missing one of limbs \\
\hline 7 & High & Crisis is high such as ignition of equipment and body burn \\
\hline 6 & Fair & Crisis is low such as bruise and little food poisoning \\
\hline 5 & Low & Crisis is very low such as bruise and little food poisoning \\
\hline 4 & Very low & Crisis is very low but most of people feel it like gas leakage \\
\hline 3 & Fine & Fine effect will remain such as hand scratch during paring \\
\hline 2 & Very fine & Very fine effect \\
\hline 1 & Without effect & Nothing \\
\hline
\end{tabular}

RPN was obtained from multiplying the severity, occurrence and recovering of the risk.
The ranges of these three factors are between 0 to 10 (Tables 1, 2 and 3).

Table 2: Probability ranking

\begin{tabular}{|c|c|c|}
\hline Ranking & Effect & Failure level \\
\hline 10 & $\begin{array}{l}\text { Very high: the occurrence of } \\
\text { error is inevitable }\end{array}$ & $\begin{array}{c}\text { More than one failure in a day and or more than } 3 \text { failures in } 10 \\
\text { operations }\end{array}$ \\
\hline 9 & $\begin{array}{l}\text { Very high: the occurrence of } \\
\text { error is inevitable }\end{array}$ & $\begin{array}{c}\text { An incidence in } 3 \text { or } 4 \text { days and or probability of } 3 \text { incidences in } 10 \\
\text { times }\end{array}$ \\
\hline 8 & High: many errors occur & An incidence in one week and or probability of 5 incidences in 100 times \\
\hline 7 & High: many errors occur & An incidence in a month and or one incidence in 1000 times \\
\hline 6 & $\begin{array}{l}\text { Fair: sometimes there is } \\
\text { probability of fault }\end{array}$ & An incidence within 3 months and or 3 incidences in 1000 times \\
\hline 5 & $\begin{array}{l}\text { Fair: sometimes there is } \\
\text { probability of fault }\end{array}$ & $\begin{array}{l}\text { An incidence within 6months to one year and or one incidence in } 10000 \\
\text { times }\end{array}$ \\
\hline 4 & $\begin{array}{l}\text { Fair: sometimes there is } \\
\text { probability of fault }\end{array}$ & one incidence in a year and or one incidence in 10000 times \\
\hline 3 & $\begin{array}{l}\text { Fine: the numbers of errors are } \\
\text { very low }\end{array}$ & An incidence within 1 to 3 years and or 6 incidences in 10000000 times \\
\hline 2 & $\begin{array}{l}\text { Fine: the numbers of errors are } \\
\text { very low }\end{array}$ & An incidence within 3 to 5 years and or 2 incidences in billion times \\
\hline 1 & $\begin{array}{l}\text { Approximately never: the } \\
\text { occurrence of fault is unlikely }\end{array}$ & $\begin{array}{l}\text { An incidence within more than } 5 \text { years and or more than } 2 \text { incidences in } \\
\text { billion times }\end{array}$ \\
\hline
\end{tabular}

RPN score is calculated by multiplying three mentioned factors according to table 4, so that RPN more than 100 are unacceptable according to similar studies and decision of expert team and then the required corrective actions were prioritized. In this study, after calculating RPN, proper corrective actions were advised to reduce the risk of possible accidents.

Table 3: Detection

\begin{tabular}{|c|c|c|}
\hline Ranking & Detection ability & Scale: the probability of hazard detection \\
\hline 10 & Absolutely nothing & $\begin{array}{c}\text { There is not any control and or if there is any control it is not able to detect the } \\
\text { potential hazard. }\end{array}$ \\
\hline 9 & Very insignificant & There is insignificant probability to detect the hazard with current controls. \\
\hline 8 & Insignificant & There is insignificant probability to detect the hazard with current controls. \\
\hline 7 & Very low & There is very little probability to detect the hazard with current controls. \\
\hline 6 & Low & There is little probability to detect the hazard with current controls. \\
\hline 5 & Fair & It is possible to detect the potential hazard with current controls in half of the cases. \\
\hline 4 & Rather high & There is rather high probability to detect the potential hazard with current controls. \\
\hline 3 & High & There is high probability to detect the potential hazard with current controls. \\
\hline 2 & Very high & There is very high probability to detect the potential hazard with current controls. \\
\hline 1 & Almost inevitable & Almost inevitable, the potential hazard will be detected with current controls. \\
\hline
\end{tabular}


Table 4: Priority levels of corrective actions according to RPN

\begin{tabular}{ccc}
\hline RPN value & Risk level & Requirements \\
\hline $200-1000$ & High & The activity should be stopped. The urgent action is necessary. \\
\hline $100-200$ & Average & Corrective actions should be performed in near future as soon as possible. \\
\hline $0-100$ & Low & The hazards should be omitted very soon but the condition is not emergency. \\
\hline
\end{tabular}

RPN: Risk priority number

\section{Results}

After completing FMEA work sheets, 105 failure modes were surveyed as a whole and risk prioritization were conducted based on RPN and also corrective actions were presented so that the highest value of RPN was 150 and the lowest value was 24 and the RPN ranged between 24 and 150 . Because of high numbers of FMEA work sheets, one example of work sheets is shown in table 5. As shown in table 5, high value of calculated RPN were related to the risk of not enough air ventilation inside the vessel in anticorrosion and welding operations of TK601A/B vessel with RPN 150 , gasket installation with RPN 120, and valves carriage by crane from the workshop to Unit600 with RPN 108, consecutively. So $11.43 \%$ of studied failure mode had RPN more than 100 .

Table 5: Failure mode and effects analysis (FMEA) work sheet

\begin{tabular}{|c|c|c|c|c|c|c|c|c|c|}
\hline Activity & Cause of defects & $\begin{array}{c}\text { Potential of } \\
\text { hazard } \\
\text { occurrence }\end{array}$ & $\begin{array}{l}\text { Effects } \\
\text { of } \\
\text { defects }\end{array}$ & Recommended actions & $\mathrm{C}$ & $\mathrm{P}$ & $\begin{array}{c}\text { Risk } \\
\text { coefficient }\end{array}$ & $\begin{array}{l}\text { Recove } \\
\text { ry }\end{array}$ & RPN \\
\hline $\begin{array}{l}\text { Removing } \\
\text { corrosion } \\
\text { and } \\
\text { welding } \\
\text { inside } \\
\text { TK601A/B } \\
\text { vessel } \\
\end{array}$ & $\begin{array}{l}\text { Lack of ventilation } \\
\text { inside the vessel } \\
\text { and not using of } \\
\text { appropriate } \\
\text { respiratory masks }\end{array}$ & $\begin{array}{c}\text { Gas } \\
\text { intoxication }\end{array}$ & $\begin{array}{l}\text { Suffoca } \\
\text { tion }\end{array}$ & $\begin{array}{l}\text { Work permit, } \\
\text { ventilating the vessel } \\
\text { before starting the } \\
\text { activity, use of specific } \\
\text { mask }\end{array}$ & 3 & 10 & 30 & 5 & 150 \\
\hline $\begin{array}{l}\text { Opening } \\
\text { PSVs and } \\
\text { valves that } \\
\text { require test } \\
\text { in aspect of } \\
\text { operation } \\
\end{array}$ & Leakage of valves & $\begin{array}{l}\text { Explosion- } \\
\text { fire accident }\end{array}$ & $\begin{array}{l}\text { Life } \\
\text { hazards }\end{array}$ & $\begin{array}{l}\text { Ensuring of not } \\
\text { leakage-installing the } \\
\text { fire extinguishers in } \\
\text { appropriate intervals, } \\
\text { considering safety } \\
\text { during the work }\end{array}$ & 3 & 10 & 30 & 4 & 120 \\
\hline $\begin{array}{l}\text { Carrying } \\
\text { PSV valves } \\
\text { from } \\
\text { workshop } \\
\text { to Unit600 } \\
\end{array}$ & Overweight object & $\begin{array}{l}\text { Falling } \\
\text { objects on } \\
\text { the hands, } \\
\text { feet and } \\
\text { body }\end{array}$ & $\begin{array}{l}\text { Break } \\
\text { and } \\
\text { injury }\end{array}$ & $\begin{array}{l}\text { Appropriate handling, } \\
\text { wearing of safety shoes }\end{array}$ & 3 & 9 & 27 & 4 & 108 \\
\hline $\begin{array}{c}\text { Removing } \\
\text { the } \\
\text { corrosion } \\
\text { and } \\
\text { welding } \\
\text { inside } \\
\text { TK601A/B } \\
\text { vessel }\end{array}$ & $\begin{array}{l}\text { Vapors of } \\
\text { electrodes }\end{array}$ & $\begin{array}{l}\text { Respiratory } \\
\text { system }\end{array}$ & $\begin{array}{l}\text { Respira } \\
\text { tory } \\
\text { disease }\end{array}$ & $\begin{array}{l}\text { Applying of welding } \\
\text { respiratory mask }\end{array}$ & 3 & 7 & 21 & 5 & 105 \\
\hline $\begin{array}{l}\text { Installing } \\
\text { new filter } \\
\text { instead of } \\
\text { old one } \\
\end{array}$ & Wastes & $\begin{array}{l}\text { Blocking of } \\
\text { filter holes }\end{array}$ & $\begin{array}{l}\text { Path } \\
\text { blockin } \\
\mathrm{g}\end{array}$ & $\begin{array}{l}\text { Ensuring of correct } \\
\text { filter holes }\end{array}$ & 3 & 6 & 18 & 3 & 54 \\
\hline $\begin{array}{c}\text { Gasket } \\
\text { installation }\end{array}$ & $\begin{array}{l}\text { Inappropriate } \\
\text { gasket }\end{array}$ & $\begin{array}{c}\text { Not } \\
\text { tolerating } \\
\text { the pressure- } \\
\text { leakage- } \\
\text { explosion }\end{array}$ & $\begin{array}{c}\text { Life } \\
\text { damage } \\
\text { S }\end{array}$ & $\begin{array}{c}\text { Supplying and usage of } \\
\text { suitable and standard } \\
\text { gasket }\end{array}$ & 2 & 9 & 18 & 3 & 54 \\
\hline
\end{tabular}

RPN: Risk priority number 
As shown in table 5, the operation of removing corrosion and welding inside TK601A/B vessel had RPN 150 for which the risk factor is incomplete ventilation inside the vessel or not using proper respiratory mask. The damage in mentioned activity is suffocation so that for prevention of such accident, the following suitable measures should be conducted: first, the required permit should be gained then the ventilation inside the vessel should be performed completely and ultimately the welding could be done, and also the proper personal protective equipment should be worn during the welding.

Also according to table 5 for the activity of opening PSVs and valves that required the test in aspect of operation, RPN was 120 for which the leakage of the valves are the reason of explosion and fire that contributes to fatal hazards. With reliance of not leakage, consideration of safety and installation of the fire extinguishers, the possibility of accident occurrence could be reduced.

\section{Discussion}

The analysis of equipment faults by FMEA method leads to recognition of different reasons that have the potential of creating hazardous condition or damaging operation phases. Also, one of the important goals of FMEA is increasing the reliability of studied systems (14).

In this regard, after studying the faults of system, development of corrective actions in the system could help to improve the system reliability. Also, in this research, after performing the surveys, the required advises were presented for improvement (14).

Based on table 4, failures with RPN > 100 need corrective action and $11.43 \%$ of 105 studied failure modes had RPN more than 100 . Also one of the failures that had high score was corrosion inside TK601A/B tank that may result from lack of regular programs of suitable maintenance which leads to leakage of toxic and dangerous materials to the environment. Ghahremani et al. in the study of failure modes analysis of process equipment in a chemical industry concluded that one of the important recognized failures was the corrosion of the equipment body that may result in leakage of toxic and dangerous materials to the environment and then intoxication, explosion or combustion. It is noticeable that regular plans of inspection and maintenance could have decreased the risk rate (14).

As table 5 illustrates, if the ventilation of TK601A/B tank is not complete before entering inside it to weld, the RPN of corrosion removing and welding failure mode will be 150 that may lead to suffocation accident and gas intoxication. This process also needs accurate analysis. As the table illustrates, for prevention of such accidents, one solution is wearing an appropriate mask. Not applying appropriate PPE (Personal protection Equipment) may be due to human error in the aspect of recognition, but FMEA could not assess it carefully. Also considering all possible conditions is time consuming and risks may have different figures based on analyzer's view and his/her skills and knowledge about system and human as part of the system so that in the study of liquid gas tanks, Nejad Ali et al. declared that applying FMEA method require a complete knowledge of system function and compartments and mentioned the time consumption and limitation of this method in ignoring the human error (11). Wang et al. in the study of developing of risk management by FMEA to correct the continuous catalysts, mentioned that FMEA has developed by the subjective information of field experts, that is to say the results of this technique is dependent on personal imagination and skills in analysis of system (4).

According to table 5, failure of new filter installation instead of old ones with occurrence possibility 3, risk severity 6 and detection figure 3, will result in RPN 54 and the failure of gasket installation with occurrence possibility 2, risk severity 9 and detection figure 3, will have same RPN value. This is in 
the condition that both of the failures have the same RPN while the risk severity coefficient of gasket installation failure was 9 with improper gasket locating and risk severity coefficient of filter installation was 6 . However, to prioritize based on RPN, both of them have the same score. So it can be concluded that FMEA technique in this case has weakness. Nejad Ali and et al. have also mentioned this subject in their study (11). And also Narayanagounder et al. in their study with the title of "new method for prioritization of failure coefficient in FMEA by ANOVA" stated that prioritization of risk when two or several failures have same RPN or severity figure and occurrence possibility and detection figure have the same significance are the faults of FMEA method. They used ANOVA to compare the average RPN and SPSS software to analyze the data to remove the technique faults $(6,15,16)$.

\section{Conclusion}

Based on the analyzer's viewpoint, ability and knowledge about system and human (as parts of the system), the risks may have different figures, so applying FMEA method requires complete knowledge about system function and its components. It is necessary to mention that some of the faults are consequences of human error but this technique cannot assess them carefully by itself.

\section{Acknowledgement}

We thank Sarkhouno Qeshm Gas Refinery Company especially Health, Safety and Environment Department.

Conflict of interest: None declared.

\section{References}

1. Kalantarnia M, Khan F, Hawboldt K. Modelling of BP Texas City refinery accident using dynamic risk assessment approach. Process Saf Environ Prot 2010; 88(3):191-9.
2. Adl J. Safety performance in the industry and its close relationship with Occupational Health. Journal of Industry and Safety 1992; 21:30-35.

3. Adl J, Mohseni M. Assessment of the effectiveness of detection techniques to identify existing hazards in the industry. Journal of School of Public Health and Institute of Public Health Research 2012; 10(1):25-32.

4. Wang $\mathrm{Y}$, Cheng $\mathrm{G}, \mathrm{Hu} \mathrm{H}, \mathrm{Wu}$ W. Development of a risk-based maintenance strategy using FMEA for a continuous catalytic reforming plant. J Loss Prev Process Ind 2012; 25(6):958-65.

5. Carbone TA, Tippett DD. Project risk management using the project risk FMEA. Engineering Management Journal 2004; 16(4):28-35.

6. Chauhan A, Malik RK, Sharma G, Verma M. Performance evaluation of casting industry by FMEA 'A case study'. International Journal of Mechanical Engineering Applications Research 2011; 2(2): 113-21.

7. Arabian-Hoseynabadi $\mathrm{H}$, Oraee $\mathrm{H}$, Tavner PJ. Failure Modes and Effects Analysis (FMEA) for wind turbines. International Journal of Electrical Power and Energy Systems 2010; 32(7):817-24.

8. Dudek-Burlikowska M. Application of FMEA method in enterprise focused on quality. Journal of Achievements in Materials and Manufacturing Engineering 2011; 45(1):89102.

9. Sultan Lipol L, Haq J. Risk analysis method: FMEA/FMECA in the organizations. International Journal of Basic \& Applied Sciences 2011; 11(5):49-57.

10. Guevara Carazas FJ, Martha de Souza GF. Availability analysis of gas turbines used in power plants. International Journal of Thermodynamics 2009; 12(1):28-37.

11. Nejadali H, Mortazavi SB, Khavanin A. LPG storage spheres risk assessment with FMEA and ETBA. Journal of Kermansha University of Medical Sciences (Behbood) 2008; 12(2):180-9.

12. Alimohammadi I, Adl J. The comparison of safety level in kilns in two gypsum production factories by Failure Modes and Effects Analysis (FMEA). Iran Occupational Health Journal 2008; 5(1,2):77-83.

13. Ghahremani A, Adl J, Nasl Seraji J. Process equipment failure mode analysis in a chemical industry. Iran Occupational Health Journal 2008; 5(1,2):31-8.

14. Heidari MH, Salmani H, Nazari Y. Usage of Failure Mode \& EffectAnalysis Method (FMEA) forsafety assessment in a drug 
manufacture. Iran Occupational Health Journal 2006; 3(1):70-5.

15. Arvanitoyannis IS, Varzakas TH. Application of failure mode and effect analysis (FMEA) and cause and effect analysis for industrial processing of common octopus (Octopus vulgaris) Part II. Int J Food Sci Technol 2009; 44(1):79-92.

16. Narayanagounder S, Gurusami K. A new approach for prioritization of failure modes in design FMEA using ANOVA. World Acad Sci Eng Technol 2009; 3(1):73-80. 